\title{
O DEBATE - POSSÍVEL - ENTRE MATERIALISMO REDUCIONISTA E FENOMENOLOGIA
}

\author{
Urbano Mestre Sidoncha \\ Universidade da Beira Interior / IFP
}

\section{Da possibilidade - e necessidade - de um debate entre materialismo e fenomenologia}

Falar do debate entre materialismo reducionista e fenomenologia é, indiscutivelmente, um exercício cuja legitimidade não se obtém de imediato, num só lance. Aparentemente, trata-se de um debate que não foi solicitado por nenhuma das partes, convictas que estão da "incomunicabilidade" dos seus procedimentos, e do gigantesco hiato que separa as perspectivas, procedimentos, orientações e naturezas de cada uma das respectivas disciplinas. Diremos, porém, que, por entre os incontáveis factores de divergência, existem outros tantos "indícios" que, devidamente equacionados, nos permitem ampliar substancialmente o até agora exíguo espaço de relação entre materialismo reducionista e fenomenologia. Isto não significa, naturalmente, que, ao atentar nesses indícios, se possa transformar, subitamente, aquilo que antes era o fosso intransponivel entre perspectivas antagónicas numa estreita e frutuosa relação. O que há de verdadeiramente decisivo nessa tentativa não é, pois, a súbita conversão do debate (cuja legitimidade há pouco se questionava) num conceito que é, per se, imediatamente transparente, nem tão pouco a construção de um terreno comum capaz de, por si só, aplanar as diferenças que nos levaram a ver, nos potenciais pontos de convergência, simples indicios para uma noção mais construtiva de debate. Dito de uma forma liminar, continua a ser dificil pensar no diálogo entre materialismo reducionista e fenomenologia, e essa dificuldade não resulta senão da diferença própria entre perspectivas que tomam, como decisões teóricas de fundo, orientações diametralmente opostas: de um lado, um materialismo reducionista que vê no tópico da idealidade da consciência um equivoco que é necessário desfazer, como a única estratégia 
que é capaz de pôr em evidência os mecanismos materiais que explicam as nossas funções de consciência e, de outro, nos antípodas dessa tese, uma fenomenologia que encontra na afirmação da idealidade (ou seja, da consciência como estrutura a priori, e não como realidade dada na ojectivação empírico-natural) anteriormente recusada um momento essencial para a sua própria constituição. Porém, do que agora se disse, resulta não tanto, como se pretendia, um processo de interna clarificação dessa noção preliminar de diálogo, mas, de novo, a concretização de uma estratégia que aponta para uma efectiva separação entre os dois campos. Pese embora a argumentação ziguezagueante que temos até agora patenteado, devemos fazer notar que ela tem, na sua génese, um motivo que recusa ambiguidades, e uma orientação bem definida: mostrar que o debate não é fácil, pelos motivos aduzidos antes, mas também que não é impossível. Ora, se é certo que a primeira afirmação não carece de maiores esclarecimentos, é igualmente certo que ainda não se vislumbra o ponto exacto a partir do qual é possível recusar a impossibilidade do diálogo.

Mas, antes de nos ocuparmos dessa tarefa, e para sermos inteiramente justos, devemos lembrar que o programa apresentado em 1996 por Francisco Varela, a que chamou Neurofenomenologia, nasce justamente da assunção de que o diálogo que propomos é, não apenas impossível, mas, ao contrário, absolutamente necessário para a superação do chamado hard problem da consciência. Definida, desde o início, como uma estratégia que visa "combinar a moderna ciência cognitiva com uma abordagem disciplinada da experiência humana",, a Neurofenomenologia de Varela revela, porém, algumas dificuldades, sobejamente conhecidas e discutidas: desde logo, e em primeiro lugar, o carácter excessivamente formal e programático dessa abordagem nova, que resulta num embaraço, mais ou menos evidente, sempre que se trata de consubstanciar a referida harmonização entre fenomenologia e o campo das ciências cognitivas; acresce a isso uma segunda dificuldade, porventura mais arrevesada que a anterior, que se prende com a natureza mesma da "comunidade de investigação" apontada pela Neurofenomenologia como vértice indispensável da sua própria estratégia: é que a ideia dessa comunidade parece fazer tábua rasa das diferenças inalienáveis entre materialismo reducionista e fenomenologia, transformando, como num passe de mágica, divergências de fundo em pontos que mutuamente se condicionam e mutuamente se esclarecem. Como sublinhamos antes, a constituição de um terreno comum não deve fazer esquecer as diferenças profundas (diríamos, as salutares diferenças) entre as respectivas orientações: tal significa que a concretização do debate não é a simples exibição de uma situação de facto, mas, antes, uma exigência cuja legitimidade deve ser posta em discussão. Donde, a superação das dificuldades 
da Neurofenomenologia (entendida em sentido lato, como uma das acepções possíveis para o debate que propomos) requer, em primeiro lugar, que se encontre um ponto concreto a partir do qual seja possível surpreender, efectivamente, o trânsito entre fenomenologia e materialismo, mas requer, igualmente, a assunção da própria necessidade desse trânsito que, por via desse ponto de intersecção, então se estabelece. Isto significa que o êxito do nosso empreendimento depende, em larga medida, da capacidade em patentear, ou não, que o materialismo reducionista invoca (embora sem o ambicionar) a fenomenologia. É dessa tarefa prioritária que nos ocuparemos de imediato.

\section{Do materialismo reducionista à Fenomenologia}

A tese que procuraremos sustentar, de seguida, é a que define que o encontro entre materialismo reducionista e fenomenologia se dá, precisamente, naquela que é a reivindicação matricial da fenomenologia de Husserl: a exigência de regresso aos fenómenos, isto é, do recuo às instâncias originárias onde o próprio mundo se constitui, e onde a consciência e seus actos são definidos como condições de possibilidade para a própria emergência do mundo, em total oposição à assunção ingénua de uma realidade de antemão dada, que justamente caracteriza a atitude natural.

Ora, afirmada assim, esta parece ser menos a equação de uma ponte entre fenomenologia e materialismo reducionista, do que a constatação das insuperáveis diferenças entre ambas. Com efeito, é justamente a pretexto deste regresso aos fenómenos que Husserl descobre a necessidade de desactivar uma compreensão empírico-natural da consciência, a mesma que tornaria imediatamente evidente um eventual nexo entre as duas disciplinas. Mas, de novo, essa conclusão não corta cerce a possibilidade do debate; ela traduz, tão só, o facto de estarmos ainda a laborar no terreno elementar das diferenças entre fenomenologia e materialismo, ou a circunstância de ainda não ter sido possível superar a perspectiva que não concebe que uma eventual "ponte" se estabeleça sem a prévia diluição dessas diferenças. Ora, a assunção de uma tal perspectiva ignora um aspecto que nos parece, a todos os títulos, essencial: a constituição de uma zona de intersecção (que serve aqui de contraponto à ideia de uma comunidade de investigação) não se faz, apenas, por via da directa correspondência entre pontos de difícil assimilação, ou pela homogeneização espontânea das diferenças, mas, ao contrário, encontrando, nessas diferenças, o estimulo necessário para um salutar exercício de reformulação de orientações e estratégias. Sejamos claros: se a fenomenologia se funda numa decisão teórica de fundo que é contrária à conclusão do materialismo de índole reducionista, isso não significa que o debate não é exequível, mas tão somente que é na assunção dessa diferença, que agora se reconhece, que se funda a possibilidade mesma da sua concretização. Ademais, não podemos descurar que a 
incorporação dessa tese fundadora da fenomenologia no quadro da perspectiva materialista só ganha contornos verdadeiramente decisivos a partir do momento em que se torna manifesta a incapacidade desse materialismo em responder de forma cabal, e conclusiva, ao problema da consciência; ora, essa conclusão é tão mais importante quanto ela se obtém por uma estratégia pautada pela sistemática desvalorização do mental, que, como fizemos notar na ${ }^{\mathrm{a}}$ Parte, constitui a própria essência do materialismo reducionista. Mas, da constatação dessa dificuldade, e da conclusão de que ela está hipostaseada numa promessa de exclusão do mental, desponta a ideia conexa de que só uma estratégia inversa de regresso ao mental pode contrariar essa lógica de sucessivos adiamentos na tarefa de explicação do problema da consciência. É pois na diferença, e na assunção plena da diferença, que podemos surpreender um primeiro contacto entre fenomenologia e materialismo reducionista.

Porém, esta exigência de regresso aos fenómenos, a partir da qual se perspectiva essa primeira associação entre fenomenologia e materialismo, só poderá, de jure, ser afirmada no momento em que se determina que o desenlace da abordagem que é feita no quadro do materialismo reducionista implica, de facto, uma supressão ou, pelo menos, uma fortíssima "desvalorização" dos fenómenos mentais. Efectivamente, não faria sentido imputar à exigência de regresso aos fenómenos mentais a responsabilidade de estabelecer um primeiro nexo com a fenomenologia se, na verdade, a própria questão desse regresso se não colocar. Dito de outra forma, a fenomenologia só poderá ser apelativa uma vez determinada a supressão ou depreciação dos fenómenos mentais como corolário, e consequência "natural", de um materialismo reducionista. Procuraremos, de seguida, argumentar em favor dessa tese. Mas uma tal conclusão impõe-nos, desde logo, um esforço adicional de clarificação: que é que implica essa exclusão dos fenómenos mentais? A tese materialista, a perspectiva reducionista, ou ambas? Numa palavra, de que lado está o eliminacionismo?

\section{O Fisicalismo reducionista e a "conclusão eliminacionista" como etapa intermédia que conduz à Fenomenologia}

No entanto, apresentada assim abruptamente, esta questão não capta ainda o significado teórico da nossạ problematização em toda a sua amplitude. A exigência de regresso aos fenómenos mentais não se coloca apenas, como sugere a nossa questão, no momento em que se determina, eo ipso, a inexistência de tais fenómenos, proposta pela tese eliminacionista. Dito de forma diversa, a exigência de regresso aos fenómenos não pode entrar em cena apenas na situação limite em que é decretada a supressão dos fenómenos mentais, mas, ao contrário, sempre que está em causa uma depreciação tal, que dificilmente se distingue do próprio eliminacionismo. A desvalorização dos fenóme- 
nos mentais não pode, pois, ficar na sombra como uma questão menor, que não se inscreve no espaço problemático onde se joga e determina a importância da fenomenologia, entendida ainda, de forma incipiente (mas que serve os nossos propósitos imediatos), como essa exigência de regresso aos fenómenos de consciência.

Esta observação tornar-se-á manifesta tão-só perguntemos: por que razão fazemos recuar a exigência de regresso aos fenómenos mentais para uma simples depreciação da nossa vida mental? Não será esse um critério demasiado "largo", que torna qualquer conclusão susceptível de constituir uma ameaça para a afirmação dessa classe de fenómenos? Atentemos no exemplo de John Searle. São bem conhecidas (tratá-mo-las, de resto, na I ${ }^{a}$ Parte) as razões de fundo que o levam a criticar, fortemente, a perspectiva funcionalista; tais razões consubstanciam-se num único argumento, que chama a si o fulcro da sua posição: a perspectiva funcionalista implica a anulação ou supressão dos fenómenos mentais, o que é um contra-senso, atendendo às características que, segundo o mesmo Searle, atestam justamente essa existência entretanto ensombrada pelo funcionalismo. Mas o passo subsequente na argumentação do autor não é menos conhecido, e a sua afirmação de que o problema mente/corpo não seria mais misterioso que o problema digestão/estômago é hoje invariavelmente mencionada como a expressão última e acabada do reducionismo fisicalista, uma tese cujo corolário parece ser (essa é também a nossa leitura) o anúncio formal da supressão dos fenómenos mentais. Um olhar ainda incipiente encontrará, aqui, a suspeita de uma contradição insanável: de facto, como compatibilizar a existência dos fenómenos mentais com uma estratégia, se essa estratégia parece estar vinculada à perspectiva contrária, leia-se, à dissolução desses fenómenos? O problema adensa-se quando percebemos que essa suspeita de contradição resiste a uma segunda análise. Como ultrapassar, então, este impasse? Notemos, porém, que a resposta está já prefigurada no horizonte das considerações feitas atrás, onde justamente demos conta da necessidade de encontrar um critério mais largo para a definição do ponto exacto onde a questão do regresso aos fenómenos mentais se deverá colocar. Concretizemos: podemos afirmar, sem mescla de ambiguidade, que Searle suprime os fenómenos mentais? Não, uma vez que é o próprio quem, explicitamente, afirma o propósito contrário, mesmo usando uma estratégia reducionista. $\mathrm{O}$ passo seguinte para resolver esta controvérsia exige, agora, que perguntemos: qual o papel dos fenómenos mentais, por exemplo, no quadro do problema da mente/corpo? Aparentemente nenhum, uma vez que, a tais ocorrências mentais, é apenas reconhecido um direito formal à existência, mas uma existência que, por isso mesmo, está privada de qualquer função concreta. Vemos assim que a suposta afirmação dos fenómenos mentais não ultrapassa esse plano estritamente formal, e que (repetindo a bem conhecida expressão do próprio Searle) o papel da mente será tão inócuo quanto o é a espuma da onda para a própria onda. Perguntemos ainda: pode esta conclusão alhear-se da exigência fenomenológica de regresso aos fenómenos mentais? Claramente, não! 
Temos vindo a defender, há muito, a noção de Relação como núcleo fundamental para pensar a consciência como problema. Num trabalho recente, procurámos evidenciar a sua eficácia enquanto instrumento para pensar o problema da consciência:

A relação é um núcleo fundamental para pensar a consciência como problema; sua principal utilidade, do ponto de vista estritamente metodológico, será justamente assegurar que a consciência não será dissolvida em nome da eficácia de qualquer esforço teórico para a sua dilucidação. Isso significa que a dissolução do problema da consciência não pode ser edificado em detrimento da própria consciência, implicando a sua dissolução. [...] se o problema consiste em saber como é que a consciência pode emergir de um corpo, tal implica, desde logo, que não posso omitir uma das variáveis fundamentais para pensar o próprio problema, que é exactamente a consciência, e suas experiências. [...] O tratamento eficaz do problema da consciência requer, como sua condição inalienável, a assunção, sem hesitações, dos termos em que ele se coloca, e é nisto, precisamente, que a noção de relação parece ser extremamente eficaz ${ }^{2}$;

Tais considerações, embora preliminares, permitem, desde já, que se extraia um princípio da maior importância: o respeito pela relação não se compadece com uma perspectiva em que um dos termos relacionais surge inteiramente subalternizado em relação ao(s) outro(s). Todavia, essa parece ser a perspectiva de Searle (ou, pelo menos, o desfecho inevitável que se obtém da sua argumentação) em relação à nossa vida mental, quando afirma, contra Nagel, que o problema da mente/corpo não é diferente do problema digestão/estômago, o que equivale dizer que a redução, no plano mental, não é substancialmente diferente de outro tipo de reduções, devendo, de resto, esperar-se a mesma eficácia explicativa.

Fica assim clarificada, e (esperemos) legitimada, a nossa tese de que a exigência de regresso aos fenómenos mentais (que caracteriza a fenomenologia de matriz husserliana) se impõe, com igual acuidade, nos casos em que a perspectiva reducionista se cifra na supressão dos fenómenos mentais (caso do eliminacionismo), mas também, e por força das conclusões referentes ao tópico da relação, na situação em que, a esses fenómenos mentais, é apenas reconhecida uma subsistência estritamente formal, e, como tal, vazia (caso do epifenomenalismo). Deve, no entanto, reconhecer-se que será mais difícil reivindicar a necessidade de regresso aos fenómenos mentais nesta última situação, uma vez que, em tese, a questão do regresso não se deve colocar nos casos em que, verdadeiramente, nunca houve abandono dessa perspectiva. Por

2 Vide Urbano Mestre Sidoncha, "A consciência e as Fronteiras do Humano", in Pedro M.S. ALVES, José Manuel SANTOS, Alexandre Franco de SÁ (Coordenadores), Humano e Inumano: A Dignidade do Homem e os Novos Desafios - Actas do II Congresso Internacional da AFFEN, Lisboa, Centro de Filosofia da Universidade de Lisboa, 2006. 
outras palavras, só a conclusão eliminacionista pode lograr, com inteira eficácia, e sem grande celeuma, o encontro com a ideia que é tão cara à fenomenologia de um regresso aos fenómenos mentais. Por isso mesmo, vamos deter-nos agora na situação em que é mais difícil resistir a esse apelo nuclear da fenomenologia, quer dizer, nas perspectivas que concluem, justamente, pela supressão dos fenómenos mentais. Por ora, importa mostrar que esse diagnóstico não afecta todas as perspectivas materialistas, mas apenas o materialismo dito reducionista.

\section{O eliminacionismo como circunstância específica do reducionismo mente/corpo}

De facto, dizer que o materialismo, no seu conjunto, conduz invariavelmente ao eliminacionismo é passar inteiramente ao lado da discussão hodierna que domina o debate sobre a perspectiva materialista. Existem, aliás, formas claras de materialismo não-reducionista (o emergentismo e a sobreveniênciavia monismo anómalo são, como vimos, os exemplos mais conhecidos dessa peculiar forma de materialismo), cujo factor distintivo, em relação às suas congéneres materialistas, é, justamente, a afirmação da existência de fenómenos mentais, mesmo quando essa existência (e essa é uma crítica que não pode ser escamoteada) não tem outra expressão que não seja a própria afirmação formal dessa existência. Portanto, não é um qualquer materialismo que, a pretexto da necessidade de regresso aos fenómenos mentais, convoca a fenomenologia, uma vez que, como vimos, essa não é consequência inevitável da perspectiva materialista. São apenas as teorias materialistas, de índole reducionista ${ }^{3}$, aquelas em que mais claramente se pode surpreender essa propensão para a exclusão das entidades mentais.

3 Não deixa de ser curiosa, e ao mesmo tempo, sintomática, a observação atenta de Fernando Gil em relação às formas de materialismo que podem, com legitimidade, "instanciar" a conclusão reducionista. Aparentemente, uma tal conclusão está arredada do campo das formas não-reducionistas de materialismo, como é, manifestamente, o caso da sobreveniência (Vide ponto 33 da nossa tese). Não obstante a importância irrecusável do desiderato que chama a si, como princípio director que comanda todos os passos metodológicos subsequentes, e que, justamente, procura preencher um espaço que não é eficazmente suprido pelas teses e propostas hodiernas, a verdade é que, segundo Fernando Gil, essas tentativas não se distanciam tanto quanto seguramente pretendiam da conclusão reducionista: "a sua ideia [da noção de sobreveniência] de fundo é explicar, a partir da recondução do mental ao físico, como o mental pode, não obstante, apresentar algo de novo em relação ao seu substrato físico. Mas, da maneira como Kim, o seu autor, põe o problema, não há resposta possível a extrair. Ele formula três princípios: co-variação do substrato e daquilo que sobrevém, dependência daquilo que sobrevém relativamente ao substrato e não-redução daquilo que sobrevém do substrato. Ora, eu não percebo como, admitindo os dois primeiros princípios, se pode recusar o reducionismo. Não se está muito longe da ideia dos níveis de organização de Engels, em que o nível superior, embora determinado pelo inferior, não deveria reconduzir-se àquele. 
A afirmação da irredutibilidade do mental é, assim, a via mais directa para enfatizar a ideia de que os fenómenos mentais são necessários, e que o esforço de supressão do mental, que é afirmado com maior ou menor clareza no quadro do monismo reducionista, constitui uma diligência que aponta em sentido contrário ao sugerido pela ideia de relação, que, em rigor, só faz sentido num quadro em que se preservam os termos relacionais. Ora, se esse é o desfecho, como defendemos, do materialismo de matriz reducionista, e portanto, se o eliminacionismo é, no limite, o espectro que paira sobre os fenómenos mentais, encontramos, na fenomenologia, a orientação fundamental que preconizamos, e que, muito justamente, passa pelo regresso aos fenómenos mentais. Notemos, porém, que o que assim se põe em destaque não é outra coisa que uma orientação diversa do materialismo reducionista, que se desenvolve em continuidade e no respeito pela ideia de relação.

Impõe-se agora uma nota: se é verdade que, do que atrás se disse, fica clara a nossa posição em relação ao tema da redução, é igualmente certo que as observações que aí apresentámos não ultrapassam o âmbito da redução psicofisica. É importante sublinhar esta tese, uma vez que dela decorre uma segunda - e não menos central - asserção, segundo a qual a redução psicofisica configura um caso especial de redução.

Que diz, afinal, o reducionismo? Qual a sua afirmação mais determinante, ou, finalmente, qual é o horizonte de sentido para que aponta ulteriormente? Responder a esta pergunta com a afirmação de que toda a redução é, necessariamente, eliminacionista é, já o dissemos, um exercício que não é comportado nem autorizado pelas premissas do próprio argumento. Há, evidentemente, uma diferença semântica entre ambos os termos: parece evidente que a redução não implica, automaticamente, a eliminação, no sentido em que não é esse o desfecho natural e inevitável do exercício da redução. A pergunta que agora se coloca é saber se esta conclusão é consentânea com a especificidade de um exercício de redução em particular, como parece ser o caso da redução psicofísica. A nossa resposta é clara: o exercício da redução psicofisica conduz a uma situação eliminacionista. Esta tese vem colocar-nos algumas dificuldades adicionais: por um lado, i) como evitar que a apreciação deste género peculiar de redução se propague a todo a espécie e, por outro lado, ii) como sustentar a especificidade da redução psicofísica num quadro mais amplo das reduções. Quanto à primeira dificuldade, importa fazer notar que, se é razoável pensar na suposta especificidade da redução psicofísica, tal só sucede, justamente, porque se entende que a sua apreciação não pode ser arbitrariamente estendida ao conjunto das demais reduções. Um esclarecimento é, porém, devido: o nosso interesse não é engendrar uma qualquer 
epistemologia para a redução, ${ }^{4}$ mas apenas divisar um argumento capaz de obviar as dificuldades suscitadas pela observação, de resto pertinente, de que há casos de redução em que a eliminação se não verifica, e vice-versa. Essa observação pretendia sustentar a tese segundo a qual é um erro associar reducionismo e eliminacionismo. Da vasta literatura sobre o assunto, há uma passagem de Jaegwon Kim que é particularmente esclarecedora e exemplificativa desse argumento:

Alguns dirão que a opção reducionista dificilmente se distingue do eliminacionismo, que reduzir as mentes e consciências a meros padrões de actividades eléctricas numa rede de neurónios desprovidos de alma é, com efeito, renunciá-los, enquanto aspecto característico e valorizado do nosso ser. Esta reacção é compreensível mas incorrecta. Há uma franca diferença entre eliminação $e$ redução. O Flogisto foi eliminado, não reduzido; [...] As bruxas forma eliminadas, não reduzidas ${ }^{5}$

Esta passagem confirma a ideia de que, entre redução e eliminação, não há uma passagem automática ou, dito de outra forma, que entre os dois conceitos não existe uma relação lógica de implicação. Seria todavia útil que nos detivéssemos mais atentamente no argumento de Kim. Segundo o autor, o facto de se ter eliminado "pseudo-entidades" como flogisto e bruxas, sem se recorrer ao exercício da redução, mostra que há uma assimetria entre os dois conceitos, de tal forma que ambos designam realidades e situações diferentes. Não contestamos! A pergunta que se impõe é, agora, esta: por que razão eliminamos o flogisto? Evidentemente, porque não há tais coisas como o flogisto, mas também porque, do estrito ponto de vista explicativo (que é onde se situa o cerne do problema da consciência), o conceito perdeu a sua utilidade. Já não é necessário recorrer ao flogisto para explicar o fenómeno da combustão, da mesma forma que não é necessário apelar a bruxas para persuadir as crianças a uma alimentação saudável: posso simplesmente dizer que, se o não fizerem, o seu crescimento estará comprometido, ou que ficarão alguns dias privados do seu brinquedo preferido. Mutatis Mutandis, poder-se-á dizer que já não é necessário recorrer a "mentes" para explicar um determinado conjunto de fenómenos, uma vez que, agora (ou num futuro próximo), se vislumbra uma explicação mais adequada, do ponto de vista científico, ${ }^{6}$ para a

4 Esse trabalho será magistralmente conduzido por Ernest Nagel. Vide Ernest, Nagel, The Structure of Science - Problems in the Logic of Scientific Explanation, Indianapolis/Cambridge, Hackett Publishing Company, 1979.

5 Jaegwon Kim, "Fisicalismo, ou algo muito próximo", in A Explicação da Interpretação Humana (Actas da Conferência Mente e Acção III - Maio de 2001), Lisboa, 2001, pp. 99-100. Itálicos nossos.

6 A fenomenologia, reclamando-se dessa mesma exigência de cientificidade, levada todavia a um grau de maior radicalização, conclui que esse é, justamente, o factor que determina, como 
ocorrência desses mesmos fenómenos. Parece-nos, pois, que os exemplos de Kim são úteis para corroborar uma intenção que é contrária à que o próprio anuncia. No limite - estamos certos que a assunção última dos pressupostos do reducionismo psicofísico nos autoriza a esse exercício de pensar o argumento em situação limite, embora evidentemente contido nesses limites - esse será o destino comum a mentes, flogisto e bruxas, segundo a perspectiva reducionista. A partir do momento em que uma neurociência suficientemente esclarecida e apetrechada se constituir, os residuos que escapavam às malhas apertadas das ciências cognitivas serão sucessivamente eliminados, e as propriedades mentais perderão definitivamente a sua utilidade. Neste enquadramento, em que as mentes foram reduzidas, porquanto deixaram de ser necessárias, ${ }^{7}$ parece de facto razoável falar em eliminação do mental, sem que se incorra numa estratégia habilmente designada por Kim de "manobra verbal". Será, portanto, uma "mutação" do ponto de vista da modalidade a ditar, na óptica reducionista, a supressão dos fenómenos mentais.

Voltando às dificuldades que enunciámos acima, diremos, portanto, que o que permite explicar a singularidade da redução psicofísica, num quadro mais alargado das reduções é, justamente, a especificidade do próprio exercício de redução, que, ademais, é enfatizado pela natureza das propriedades a reduzir. Esta conclusão permite-nos explicar, ainda, porque é que a conclusão eliminacionista não se propaga a toda a espécie das reduções: se a implicação está condicionada pela natureza das propriedades a reduzir, a conclusão só se obterá nessa, e não noutras circunstâncias.

Curioso será notar que, se é em nome de uma maior eficácia explicativa que o reducionismo promove, inesperadamente, o eliminacionismo, é esse mesmo objectivo que, em nosso entender, impede o próprio reducionismo mente-corpo. Kim considera, em sentido diametralmente oposto, que não há alternativa ao reducionismo, embora mostre alguma reserva no que à eficácia do projecto reducionista diz respeito:

Ao levantar esta questão acerca da redutibilidade do mental, é importante não pensar que o mental como totalidade tenha de ser redutível ou irredutível. Pode muito bem ser que partes do mental sejam redutiveis e o resto não. Pode ser que

condição de possibilidade da própria ciência, o regresso aos fenómenos mentais, e a "desactivação" do empírico.

7 A declaração de Patrícia Churchland que a seguir se transcreve corrobora e amplia consideravelmente o sentido - já de si assumidamente radical - desta nossa tese: "[...] não temos necessidade de admitir um espírito ou uma alma imaterial para além do cérebro, dado que podemos explicar perfeitamente esses fenómenos em termos de propriedades cerebrais, dinâmica de circuitos, propriedades electrofísicas, etc.” B. Alan Wallace \& Houshmand, Zara \& Robert B. Livingston, (Org.), Consciousness at the Crossroads: Os Caminhos cruzados da Consciência - Conversas com Dalai Lama sobre Ciência do Cérebro e Budismo (Com participação de António Damásio), Trad. portuguesa de Filipe Valente Rocha", Porto, Asa Editores, 2001, p. 28. Itálicos nossos. 
o projecto fisicalista possa ser levado a cabo para vários sub-domínios do mental, mas não para todo [...]. Mais especificamente, a minha opinião é de que as qualidades da experiência consciente, o que é agora vulgarmente chamado "qualia", são irredutiveis, mas que temos motivos para pensar que o resto, ou grande parte dele, de qualquer forma, é redutivel ${ }^{8}$

Detenhamo-nos nestas considerações: Kim, para quem o reducionismo parece ser, no quadro da discussão entretanto expendida, a melhor opção, procura sustentar a exequibilidade dessa estratégia argumentando que, nos casos em que ela não se realiza, tal se deve apenas ao facto de, para uma parte do mental, não ser válida a opção reducionista. Que resiste à redução? Os qualia! Além disso, o autor associa essa perspectiva a um dos mais fortes opositores do reducionismo:

Eu não sou obviamente a primeira ou única pessoa a sustentar uma visão deste tipo; David Chalmers e outros defenderam, bastante plausivelmente na minha opinião, uma posição precisamente idêntica. ${ }^{9}$

A melhor defesa anti-reducionista acabará, assim, por ser feita, inadvertidamente, pelo próprio Kim, uma vez que concede, com os não-reducinostas, que os qualia colocam dificuldades insuperáveis ao reducionismo. Mas há outras formas menos rebuscadas para comprometer o reducionismo mente-corpo, e a conclusão eliminacionista, a ele associada. Atrás considerámos que a especificidade da redução não advém de outra coisa que da própria singularidade da relação, a relação mente-corpo. Neste ponto, seguimos a argumentação de Thomas Nagel, que alegava que o insucesso da redução mente-corpo se podia explicar pelo facto de a relação que lhe estava subjacente ser, efectivamente, única. Essa tomada de posição permitia compreender, por exemplo, o sucesso da redução entre água $\mathrm{e}_{2} \mathrm{O}$, mas igualmente o fracasso da tese reducionista quando transposta, sem mais, para a relação mente-corpo. Assim, se é verdade que da redução da água a $\mathrm{H}_{2} \mathrm{O}$ não resulta uma eliminação, mas antes um esclarecimento da natureza da própria água, não é menos verdade que a redução, aplicada coercivamente sobre a relação mente-corpo, resulta na eliminação das mentes, uma vez que, exposta a sua natureza corporal, perdem definitivamente a sua utilidade.

Vejamos, pois, em retrospectiva, o percurso que até agora fizemos: depois de dizer que nem todo o materialismo é reducionista, no sentido em que o reducionismo é apenas uma acepção possível, entre outras, para divisar a estratégia materialista, dizemos agora que nem todo o reducionismo é necessa-

8 Jaegwon Kim, "Fisicalismo, ou algo muito próximo", in A Explicação da Interpretação Humana (Actas da Conferência Mente e Acção III - Maio de 2001), Lisboa, 2001, pp. 100-101 .

9 Ibidem, p. 101. 
riamente eliminacionista, no sentido em que a eliminação não é uma implicação necessária do processo reducionista. Esta conclusão tem, contudo, um alcance mais largo do que o que nos é dado a perceber por um exame menos atento: ao limitar a associação entre reducionismo e eliminacionismo à circunstância específica da redução psicofísica, a acusação segundo a qual "reduzir não é eliminar" não atinge o fulcro da nossa posição filosófica, uma vez que, segundo a tese que propomos, não é despiciendo pensar numa espécie de "regime de excepção" para a redução mente-corpo, sustentando esse regime na própria especificidade da relação (e dos elementos que necessariamente a compõem) que está subjacente ao processo de redução, a saber, a relação mente-corpo. Donde, se essa é a principal fragilidade do materialismo reducionista, se essa fragilidade está associada à dificuldade em tratar convenientemente o problema da consciência, e, finalmente, se essa mesma dificuldade resulta de uma decisão precipitada de exclusão do mental, se tudo isso é verdade, então compreende-se que a fenomenologia de matriz husserliana exerça a força de um apelo irresistível, próprio de quem oferece a orientação necessária para corrigir a estratégia do materialismo reducionista. Agora, como na data da sua fundação, a fenomenologia desponta a como a única estratégia capaz de chamar a si aquela que é de facto a prerrogativa maior do pensar científico: a exigência de uma fundamentação radical.

\section{Do desacordo da Neurofenomenologia de $\mathrm{F}$. Varela em relação à Fenomenologia Transcendental de E. Husserl}

Ciente das dificuldades enfrentadas pelas ciências cognitivas no tratamento do célebre "hard problem", Francisco Varela proporá, como foi dito, um novo método cujo objectivo imediato será o de desbloquear o impasse em que se verá enredado o modelo cognitivista, nas suas múltiplas acepções e possibilidades. Inscrevendo-se explicitamente na tradição fenomenológica continental, Varela considera que o sucesso das ciências cognitivas dependerá da possibilidade de estabelecer, com a fenomenologia de Husserl, e a partir da sua célebre exigência de um regresso às coisas mesmas, uma correspondência estrita, que permita "informar" devidamente os dados objectivos obtidos pelas ciências cognitivas. Segundo Varela, a fenomenologia dispõe de um instrumento singular - o da redução fenomenológica - que lhe outorgará a possibilidade de olhar para a experiência com um olhar renovado, e que é a partir de uma tal compreensão nova da experiência que se poderão obter as necessárias correlações do lado das ciências cognitivas. ${ }^{10} \mathrm{O}$ princípio director deste novo

10 "Many of the claims made on the cognitive side, under the heading of "theory of mind", are based on neurological studies and experiments performed in the context of developmental psychology. The interpretation of these scientific studies, however, could benefit greatly from the guidance of phenomenology." Denis Fisette, "Descriptive Phenomenology and the Problem 
método, que comanda todos os passos subsequentes, e que permite uma interpretação cabal da metodologia envolvida, é o de uma research comunity, "comunidade de investigação", uma espécie de "laboratório alargado", que integre ciências cognitivas $e$ fenomenologia. Será a partir da constituição de uma tal comunidade de investigação, alega Varela, que a oposição entre primeira e terceira pessoas deixará de poder ser interpretada, sem mais, como uma oposição entre rigor e a ausência desse mesmo rigor. Uma tal proposta, conclui Varela, tem a vantagem de evitar compreensões incorrectas acerca da natureza da fenomenologia, demarcando-se assim, e de forma irreversível, das propostas de Nagel (e da sua "fenomenologia objectiva") e Dennett (e da proposta de uma heterofenomenologia) ${ }^{11}$. Denis Fisette observará que a assunção, por parte de alguns sectores nas ciências cognitivas e na filosofia da mente, da "dimensão fenomenológica" do problema não encontrará correspondência numa compreensão fidedigna da própria tradição fenomenológica: "Muitos filósofos da mente [...] reconheceram o carácter propriamente fenomenológico deste problema; Nagel está mesmo disposto a confiar o estudo da consciência fenomenal àquilo a que chama de "fenomenologia objectiva". No entanto, a fenomenologia a que estes filósofos recorrem tem pouco que ver com a estrutura conceptual que fora desenvolvida pela tradição fenomenológica." 12 Uma tal incompreensão em relação à génese que determina a novidade e a necessidade do discurso fenomenológico, prossegue Varela, é tanto mais incompreensível quanto é certo que as mudanças recentes no próprio quadro das ciências cognitivas favoreceram, largamente, essa aproximação em relação à fenomenologia: "Se começarmos por pensar na ciência cognitiva como foi primeiro formulada, em oposição ao behaviorismo, em termos de análise computacional e processamento de informação, será difícil ver como pode a

of Consciousness", in The Problem of Consciousness - new essays in phenomenological philosophy of mind (Ed. By Evan Thompson), Canadian Journal of Philosophy (supplementary volume; 29), Calgary, Alberta, University of Calgary Press, 2003, p. 33. Isso mesmo será ainda sublinhado por Dan Zahavi: "[...] analytical philosophy in its dealing with these questions might profit from looking at some of the resources found in continental philosophy. Why? Because many of the problems and questions that analytical philosophy of mind are currently facing are problems and questions that phenomenologists have been struggling with more than a century. Drawing on their results would not only help avoid unnecessary repetitions, it might also bring the contemporary debate to a higher level of sophistication." Dan Zahavi, "Intentionality and Phenomenality: A Phenomenological Task on the Hard Problem", in Ibidem, pp: 66-67.

11 "Nagel and others philosophers [...] relate the question of consciousness and of phenomenal experience to properly phenomenological problems without, however, granting much importance to the specific character of phenomenology" Denis Fisette, "Descriptive Phenomenology and the Problem of Consciousness", in Ibidem, p. 50. Itálicos nossos.

12 "Many philosophers of mind [...] have acknowledge the properly phenomenological character of this problem; Nagel is even willing to entrust the study of phenomenal consciousness to what he calls an "objective phenomenology". Yet, the phenomenology to which these philosophers resort has little to do with the conceptual framework that was developed within the phenomenological tradition". Ibidem, p. 33. 
fenomenologia participar na "Revolução Cognitiva". [...] Esta já não é, no entanto, a perspectiva actual das ciências cognitivas." ${ }^{\text {"13 }}$ Mas esta associação entre as ciências cognitivas e o terreno da fenomenologia (que não problematizaremos) não se faz sem custos para a disciplina de Husserl, pois ela imporá, como sua indeclinável condição de possibilidade, uma redefinição da própria fenomenologia: "Esta recente redefinição das ciências cognitivas, se é para incluir um lugar para a fenomenologia, solicita que concebamos igualmente a fenomenologia de uma forma diferente [...] Uma forma de pensar nisto é falar da naturalização da fenomenologia.". ${ }^{14}$ No entanto, o próprio Varela, que se reclama de um compreensão mais autêntica em relação à fenomenologia do que a dos seus predecessores, não poderia ignorar, como de resto o não faz, que se colocam imediatamente dificuldades seriíssimas a esse projecto de naturalização da fenomenologia: "Para muitos fenomenólogos, isto parecerá autocontraditório, uma antinomia. A fenomenologia é, por definição, não-naturalista. Para muitos outros, a questão difícil é a de que como se pode alcançá-la sem que se perca a especificidade da fenomenologia". ${ }^{15}$ Mas há dois passos decisivos que, segundo Varela, parecem remover os derradeiros obstáculos (os primeiros foram supostamente subtraídos pela convergência crescente das ciências cognitivas em relação à fenomenologia) à ideia de naturalização de fenomenologia. O primeiro consistirá num entendimento diverso do que significa naturalização. ${ }^{16} \mathrm{O}$ segundo consiste na invocação do já célebre $\S 57$ das Cartesianische Meditationen, onde, aparentemente, Husserl autoriza que a análise transcendental seja desenvolvida no seio da atitude natural, "bastando-lhe", para tal, abandonar ou desistir da "atitude transçendental".17 Donde, "aquilo que permite à fenomenologia husserliana subtrair-se a um esquema naturalista (a atitude natural) é uma mudança de atitude alcançada

13 "If one begins by thinking of cognitive science as it was first formulated in opposition to behaviourism, in terms of computational analysis and information processing, it is difficult to see how phenomenology might participate in the "Cognitive Revolution". [...] This, however, is no longer the current view of cognitive science." Shaun Gallagher \& Francisco Varela, "Redrawing the Map and Resetting the Time: Phenomenology and the Cognitive Sciences", in Ibidem, p. 95.

14 "This recent redefinition of the cognitive sciences, if it is to include a place for phenomenology, requires that we also conceive of phenomenology in a different way [...] One way to think of this is to think of naturalizing phenomenology" Ibidem, p. 96.

15 "For many phenomenologists, this will seem self-contradictory, an antilogy. Phenomenology just is, by definition, non-naturalistic. For many others, the difficult question is how it might be accomplished without it losing the specificity of phenomenology. Everything, however, depends on what one means by naturalization." Ibidem. Itálico nosso.

16 "Everything, however, depends on what one means by naturalization". Ibidem.

17 "Although Husserl defined phenomenology as a non-naturalistic discipline, the idea that the results of his transcendental science might inform the natural sciences is not inconsistent with his own intent. He suggested, quite clearly, that "every analysis or theory of transcendental phenomenology - including the theory of transcendental constitution of an Objective world can be produced in the natural realm, when we give up the transcendental attitude." Ibidem, p. 98. Itálicos nossos. 
por intermédio de uma prática metodológica (a redução fenomenológica). Para dirigir-se na direç̧ão oposta, isto é, para trazer a fenomenologia a acordar com o projecto das ciências cognitivas, envolve outra mudança de atitude. Mas isto não significa abandonar os métodos fenomenológicos [...]". ${ }^{18}$ Atente-se, porém, nesta afirmação: o que se preconiza como estratégia que operará a transição entre os discursos da fenomenologia e ciências cognitivas é uma "nova mudança de atitude", que aponta em sentido contrário aquele que fora engendrado pela redução fenomenológica. Mas que é, ou que pode ser uma fenomenologia que aponta em sentido oposto ao que fora já instituído, em bases sólidas, pelo instrumento da redução fenomenológica? Que é a uma fenomenologia transcendental, quando se vê privada do método que lhe permitirá uma correspondência plena com o desiderato de uma fundamentação radical? Por último, uma vez subtraído o método da redução, qual o critério de distinção que opõe derradeiramente os domínios da fenomenologia e de uma simples psicologia empírica? Como é possível que esta conversão, que aponta numa direcção outra daquela que fora prescrita pela redução, possa ainda ser integrada, com legitimidade, no seio dos métodos fenomenológicos? São questões difíceis para as quais a Neurofenomenologia insiste em não responder de forma concludente. Uma tal perplexidade é tanto mais desconcertante quanto ela se arroga de uma compreensão mais genuína da tradição fenomenológica, tal como fora magistralmente expressa por Husserl.

A ideia que está subjacente ao método da Neurofenomenologia é, no entanto, uma ideia fecunda, capaz de divisar, não obstante algumas dificuldades de fundo na compreensão da raiz e natureza últimas da fenomenologia husserliana, um sentido novo para a inscrição da discussão fenomenológica como interlocutor privilegiado na tarefa de elucidação do problema mente /corpo. Efectivamente, se é verdade que o objectivo das actuais neurociências é a constituição de um quadro completo das correspondências (ou antes, das correlações) entre os processos físicos do cérebro e os fenómenos da experiência humana, é compreensível e razoável a expectativa de Varela - a mesma que justifica e legitimará a Neurofenomenologia como método - de que a fenomenologia, entendida como uma discrição rigorosa desses fenómenos, possa, melhor do que qualquer outra abordagem disciplinar, informar as ciências neurológicas daquele que é, na verdade, o seu próprio objecto de estudo $^{19}$. Não se poderá, no entanto, questionar o alcance da Neurofenome-

18 "What allows Husserlian phenomenology to escape from a naturalistic framework (the natural attitude) is a change of attitude achieved trough a methodical practice (the phenomenological reduction). To move in the opposite direction, that is, to bring phenomenology to bear on the naturalistic enterprise of the cognitive sciences, involves another change of attitude. This does not mean abandoning phenomenological methods [...]". Ibidem. Itálicos nossos.

19 "At the heart of neurophenomenology is the claim that Husserlian phenomenology has a unique and privileged method of describing the first-person nature of consciousness. Phenomenology is unique in that it is importantly different from the standard first-person methodologies employed in consciousness studies; and it is privileged in that it is more rigorous 
nologia de Varela elegendo, como fará Tim Bayne, a fenomenologia como o "elo" mais débil de uma tal estratégia. Segundo Bayne, se a Neurofenomenologia está hipostaseada na superioridade da singular linguagem da fenomenologia como método para a clarificação dos fenómenos da experiência humana, então basta denunciar a falsidade desse princípio para comprometer irreversivelmente a própria metodologia indigitada por Varela. Bayne alcançará esse objectivo intermédio, quando declara, em clara dissensão com o mais elementar sentido dos textos de Husserl, que a reflexão fenomenológica não difere substancialmente do método da introspeç̧ão ${ }^{20}$. Porém, o que haverá a opor a uma Neurofenomenologia não será o facto de caucionar a fenomenologia como estratégia a envolver na tentativa de superação do célebre hard problem da consciência, mas, desde logo, o facto de prescrever como necessária a naturalização da própria fenomenologia - não obstante a multiplicidade de sentidos dessa ideia mesma de "naturalização" - quando o que é próprio da fenomenologia transcendental outra coisa não é do que a supressão de qualquer compromisso de naturalização.

\section{Breve Bibliografia}

NAGEL, Ernest, The Structure of Science - Problems in the Logic of Scientific Explanation, Indianapolis/Cambridge, Hackett Publishing Company, 1979

THOMPSON, Evan, (Ed.), The Problem of Consciousness - new essays in phenomenological philosophy of mind (); Canadian Journal of Philosophy (supplementary volume; 29), Calgary, Alberta, University of Calgary Press, 2003

GIL, Fernando, Acentos, Lisboa, Imprensa Nacional-Casa da Moeda, 2005

VARELA, Francisco, "Neurophenomenology: a methodological remedy for the hard problem", in Journal of Consciousness Studies $3 / 4$

KIM, Jaegwon, "Fisicalismo, ou algo muito próximo", in A Explicação da Interpretação Humana (Actas da Conferência Mente e Acção III - Maio de 2001), Lisboa, 2001

SidONCHA, Urbano Mestre, "A consciência e as Fronteiras do Humano", in Pedro M. S. ALVES, José Manuel SANTOS, Alexandre Franco DE SÁ (Coordenadores), Humano e Inumano: A Dignidade do Homem e os Novos Desafios - Actas do II Congresso Internacional da AFFEN, Lisboa, Centro de Filosofia da Universidade de Lisboa, 2006

than such methodologies ". Tim Bayne, "Closing the gap? Some questions for neurophenomenology", in Phenomenology and the Cognitive Sciences xxx, Kluwer Academic Publishers, 2004, p. 3.

20 "How does phenomenological reflection differ from introspection?", perguntará Bayne, para, volvidas apenas algumas páginas, reiterar essa suspeita em relação às virtudes da fenomenologia husserliana "[...] what reason do we have for thinking that the results of phenomenological reduction are more reliable than those of 'mere introspection'?". Ibidem, pp. 3-7. 